Original article

\title{
ANALGESIC AND SEDATIVE EFFECTS OF CAUDAL EPIDURAL TRAMADOL IN DROMEDARY CAMELS
}

\author{
O. AZARI ${ }^{1}$, S. SEYYEDIN $^{2}$, M. M. MOLAEI ${ }^{1}$, H. HASSIBI $^{1}$ \\ $\&$ B. HASHEMI MADANI ${ }^{2}$ \\ ${ }^{1}$ Department of Clinical Sciences, Shahid Bahonar University of Kerman, Iran; \\ ${ }^{2}$ Faculty of Veterinary Medicine, Shahid Bahonar University of Kerman, Iran
}

\section{Summary}

Azari, O., S. Seyyedin, M. M. Molaei, H. Hassibi \& B. Hashemi Madani, 2019. Analgesic and sedative effects of caudal epidural tramadol in dromedary camels. Bulg. J. Vet. Med., 22, No 1, 57-65.

This study aimed to investigate the analgesic efficacy of caudal epidural administration of tramadol in dromedary camels (Camelus dromedarius). A total of 10 dromedary camels of both sexes were selected and randomly assigned to one of two groups to receive epidurally either $1 \mathrm{mg} / \mathrm{kg} \mathrm{or} 2 \mathrm{mg} / \mathrm{kg}$ of tramadol hydrochloride. The injections were made into the epidural space at first intercoccygeal junction. Using a pinprick method, analgesia was tested. Duration and onset of complete perineal analgesia were determined. Ataxia and sedation were also assessed and recorded. Clinical parameters including heart rate, respiratory rate and rectal temperature were measured. The lower dose $(1 \mathrm{mg} / \mathrm{kg})$ of tramadol induced analgesia only in the tail but the higher dose produced complete antinociception in the tail, anus and perineum. Analgesia of the hind limbs was not achieved after either doses of tramadol. The mean times to onset and duration of complete analgesia in camels receiving epidural tramadol at a dose of $2 \mathrm{mg} / \mathrm{kg}$ were $22 \pm 2.55 \mathrm{~min}$ and $65 \pm 8.66 \mathrm{~min}$, respectively. Various degrees of ataxia occurred in all camels. Mild to deep sedation was observed following both doses. Mean heart rate, respiratory rate, and rectal temperature tended to increase for the first 15 or $30 \mathrm{~min}$ after injection. Based on the results of this study, analgesic effects of caudal epidural tramadol were dose dependent. Epidural tramadol at a dose of $2 \mathrm{mg} / \mathrm{kg}$ would provide suitable postoperative analgesia for various manipulations in the tail, anus and perineum in standing dromedary camels.

Key words: analgesia, camel, epidural, tramadol

\section{INTRODUCTION}

General anaesthesia of ruminants is associated to inherent risks including regurgitation of ruminal contents, excessive salivation and pulmonary complications. It is therefore rarely carried out and local or regional analgesic techniques are preferred instead (Hall et al., 2001). Epidural anaesthesia is a central neuraxial block 
technique which is practical, inexpensive and easily accessible. In veterinary medicine, caudal epidural anaesthesia is commonly used when performing diagnostic, obstetrical and surgical intervention in the perineal, sacral, lumbar and caudal parts of the thoracic region (Dehghani \& Bigham, 2009).

Lidocaine hydrochloride $(2 \%)$ is the most commonly used local anaesthetic drug for epidural analgesia in camels. However, the duration of action is short which is not suitable in long-duration surgical operations (Hall et al., 2001). The lidocaine's action is not specific to the sensory tracts and it also blocks motor and sympathetic fibres which causes weakness, hind limb ataxia and sometimes recumbency (Lee et al., 2003). Opioids and alpha-2 adrenergic agonists are also commonly used in combinations with lidocaine which results in more prolonged and adequate analgesia (Hall et al., 2001; Azari et al., 2014).

Tramadol, a synthetic 4-phenyl-piperidine analogue of codeine, is a racemic mixture which produces analgesia by both opioid and nonopioid mechanisms and acts as an inhibitor of the reuptake of monoamine neurotransmitters such as norepinephrine and serotonin (Scott \& Perry, 2000; Pathan \& Williams, 2012). Moreover, the complementary interaction between the $(+)$ and $(-)$ enantiomers of tramadol produces antinociceptive synergy, but do not summate to increase the adverse effects such as constipation and respiratory depression (Raffa et al., 1993). The overall pharmacological profile of tramadol including activation of opioid receptors, inhibition of the monoaminergic system and local anaesthetic effects makes this drug an attractive and suitable choice for epidural administration (Raffa et al., 1993; Altunkaya et al., 2003). It should be noted that besides the epidural administration of tramadol, the intravenous (IV) and the intramuscular (IM) injection of this drug have been also used so far (Elghazali et al., 2008).

The dromedary camel (Camelus dromedarius) is one of the most important domestic animals in arid and semi-arid regions including the Middle East and Africa, with smaller populations in Australia (Mburu et al., 2003; Kadim et al., 2008). Because of its unique physiological characteristics such as great tolerance to high temperatures and poor vegetation, it is considered as a good source of meat especially in areas where the climate adversely affects the performance of other meat animals (Kadim et al., 2008). Many of the principles of veterinary anaesthesia and dosage regimens applied to camelids are usually extrapolated from those recommended for other ruminant species (Pereira et al., 2006). Additionally, dromedaries may be particularly susceptible to toxicity from certain drugs at doses harmless to other ruminants (Hall et al., 2001). The purpose of this study was to investigate the analgesic and sedative efficacy of caudal epidural administration of tramadol in dromedary camels.

\section{MATERIALS AND METHODS}

\section{Animals}

A total of 10 dromedary camels of both sexes aged 4 to 6 months and weighing 180-220 kg were selected for this study. The animals were housed in the same group pen. A constant ration of grass (hay) supplemented with concentrate was offered to the animals and drinking water was made freely available. Based on clinical and haematological evaluations performed prior to the study, the camels were judged to be healthy. Food and water were 
withheld from the animals 12 and $8 \mathrm{~h}$, respectively, before the experiment. The experiment was conducted in the morning when the ambient temperature ranged between $25^{\circ} \mathrm{C}$ and $27^{\circ} \mathrm{C}$.

\section{Study design}

The experimental protocols were approved by the Research Ethics Committee of the Shahid Bahonar University Of Kerman,Iran. The animals were randomly assigned to one of two groups $(n=5)$ to receive epidurally either $1 \mathrm{mg} / \mathrm{kg}$ (T1) or $2 \mathrm{mg} / \mathrm{kg}$ (T2) of tramadol hydrochloride (50 mg/ 1ml, Tehran Chemie, Iran). Prior to injection, the lower dose was diluted in sterile saline so that both groups received the same volume $(8.8 \mathrm{~mL})$.

\section{Drug administration and determination of effects}

The animals were restrained in sternal recumbency before each treatment. After sterile preparation of the injection site, the injections were made into the epidural space at first intercoccygeal junction using a 3.7-cm-long, 18-gauge hypodermic needle. Loss of resistance and hanging drop techniques were used to identify the epidural space. Following the injection, the camels were walked into a chute and carefully monitored for any drug side effects. The observers were blinded to the drug doses administered.

Analgesia was tested in the tail, anus, perineum and upper hind limb using a pinprick method. For this purpose, a 23gauge needle was applied to the skin and advanced into the underlying tissues at the mentioned regions. The needle was inserted at slightly different sites for each test. Complete analgesia was defined as lack of response to superficial and deep pinpricks. The response to painful pinprick stimuli for each site was assessed, recorded and compared between the groups. This study focused on the time to onset and duration of complete perineal analgesia. The time between the injection and loss of sensation was considered the onset time of complete analgesia. Duration of complete perineal analgesia was determined by testing the response to stimulation of the perineal skin before (time zero) and at 1, 3, 5, 10 and 15 minutes after injection. Thereafter the response to painful stimulation was evaluated every $5 \mathrm{~min}$ until the end of complete analgesia.

Ataxia and sedation were assessed and recorded. Ataxia was assessed by observing the hindlimb position, swaying and leaning against the chute or any knuckling of the fetlocks of the hindlimbs. Based on the signs of ataxia, the animals were described as non-ataxic (no sign of ataxia; score 0 ), mildly ataxic (alteration in hind limb position; score 1), moderately ataxic (postural sway, leaning against the chute; score 2) and severely ataxic (recumbency; score 3). Sedation was rated on a fourpoint scale as follows: 0, alert (no sedation); 1, mild sedation (reduced alertness with no other signs); 2 , moderate sedation (drowsy, slightly drooping eyelids and head lowered); 3 , deep sedation (markedly drowsy, drooping eyelids and head fully lowered).

Clinical parameters including heart rate $(\mathrm{HR})$, respiratory rate $(\mathrm{RR})$ and rectal temperature (RT) were measured and recorded before drug administration and at 15 min intervals thereafter until the $120^{\text {th }}$ $\min$.

\section{Statistical analysis}

The onset time and duration of complete perineal analgesia were analysed using one-way analysis of variance (ANOVA) followed by post hoc Tukey's HSD test. 
Data for perineal analgesia were expressed as mean values \pm standard error. Values of HR, RR and RT were analysed by Mann-Whitney $U$ test to examine the differences between the groups during the 120-minute study. A Friedman's test was employed to compare the values at different time intervals with their baselines (measurements performed before drug administration) within the groups. Data for HR, RR and RT were expressed as median (min-max range). Wilcoxon signed rank test was used to analyse the sedation and ataxia scores. These scores were expressed as median (interquartile range). All statistical analyses was performed using SPSS (SPSS for Windows, v. 16.0, SPSS Inc, Chicago, Illinois). Differences were considered statistically significant when the calculated $\mathrm{P}$ value was less than 0.05 .

\section{RESULTS}

The analgesia induced by the lower dose $(1 \mathrm{mg} / \mathrm{kg}$ ) of tramadol was only limited to the tail but complete antinociception was produced in the tail, anus and perineum in all camels that received the higher dose of tramadol $(2 \mathrm{mg} / \mathrm{kg})$. Analgesia of the hind limbs was not achieved after either doses of tramadol. The mean time to onset and duration of complete analgesia in camels receiving epidural tramadol at a dose of 2 $\mathrm{mg} / \mathrm{kg}$ were $22 \pm 2.55$ min (range 15-30 $\mathrm{min}$ ) and 65 $\pm 8.66 \mathrm{~min}$ (range 45-90 $\mathrm{min}$ ), respectively.

Various degrees of ataxia occurred in all camels following epidural administration of tramadol at both doses. Most of the animals in group T1 (1 mg/kg) showed mild ataxia (score 1), whereas moderate (score 2) to severe (score 3) ataxia was observed in group T2 (2 mg/kg). Severe ataxia leading to recumbency was ob- served in only one camel in group T2. Comparison of ataxia scores between the two groups showed a significant statistical difference $(\mathrm{P}<0.05)$ (Table 1).

Table 1. Ataxia and sedation scores following epidural administration of $1 \mathrm{mg} / \mathrm{kg}$ (group T1) or $2 \mathrm{mg} / \mathrm{kg}$ (group T2) tramadol in dromedary camels. Data are expressed as median (interquartile range)

\begin{tabular}{ccr}
\hline Group & $\begin{array}{c}\text { Ataxia } \\
\text { score }\end{array}$ & $\begin{array}{c}\text { Sedation } \\
\text { score }\end{array}$ \\
\hline $\mathrm{T} 1$ & $1(0.5-1)$ & $1(1-1)$ \\
$\mathrm{T} 2$ & $2 *(2-2.5)$ & $2 *(2-2.5)$ \\
\hline
\end{tabular}

* $\mathrm{P}=0.038$ between the groups.

All animals receiving the lower dose of tramadol $(1 \mathrm{mg} / \mathrm{kg})$ showed mild sedation (score 1) while the higher dose (2 $\mathrm{mg} / \mathrm{kg}$ ) induced moderate sedation (score 2) in four animals and deep sedation (score 3) in one animal. Comparison of sedation scores between the two groups showed a significant statistical difference $(\mathrm{P}<0.05)$ (Table 1).

Mean HR, RR and RT were similar among all animals prior to injections (time zero, Table 2). All these variables tended to increase for the first 15 or $30 \mathrm{~min}$ following tramadol administration in both groups. In group T1, HR was not significantly different from their baselines during the study, except at $15 \mathrm{~min}$ after injection $(\mathrm{P}<0.05)$. $\mathrm{RR}$ were significantly different from their baselines at 15 and 30 min following tramadol injection $(\mathrm{P}<0.05)$. RT differed significantly from its baseline 30 minutes after drug administration $(\mathrm{P}<0.05)$. In group $\mathrm{T} 2, \mathrm{HR}$ and RT were significantly different from their baselines at 15 and $30 \mathrm{~min}$ following tramadol injection $(\mathrm{P}<0.05)$, while the variations of RR were only significantly different from their baselines at $15 \mathrm{~min}$ 
Table 2. Median (min-max range; $n=5$ ) values of heart rate $(H R)$, respiratory rate $(R R)$ and rectal temperature (RT) in dromedary camels at baseline (before injection) and at predetermined intervals after caudal epidural administration of tramadol at doses of $1 \mathrm{mg} / \mathrm{kg}$ (group T1) or $2 \mathrm{mg} / \mathrm{kg}$ (group T2).

\begin{tabular}{|c|c|c|c|c|}
\hline \multirow{2}{*}{ Time (min) } & \multirow{2}{*}{ Group } & \multicolumn{3}{|c|}{ Variable } \\
\hline & & HR (beats/min) & RR (breaths/min) & $\mathrm{RT}\left({ }^{\circ} \mathrm{C}\right)$ \\
\hline 0 & $\begin{array}{l}\mathrm{T} 1 \\
\mathrm{~T} 2\end{array}$ & $\begin{array}{r}59(54-62) \\
54.5(54-58)\end{array}$ & $\begin{array}{r}12(11-14) \\
12.5(11-13)\end{array}$ & $\begin{array}{r}37.1(36.9-37.2) \\
37(36.9-37.2)\end{array}$ \\
\hline 15 & $\begin{array}{l}\mathrm{T} 1 \\
\mathrm{~T} 2\end{array}$ & $\begin{array}{r}72^{*}(66-78) \\
63^{* \wedge}(62-68)\end{array}$ & $\begin{array}{l}17 *(13-17) \\
15 *(11-16)\end{array}$ & $\begin{array}{r}37.4(37.3-37.4) \\
37.5 *(37.3-37.7)\end{array}$ \\
\hline 30 & $\begin{array}{l}\mathrm{T} 1 \\
\mathrm{~T} 2\end{array}$ & $\begin{array}{r}64(60-70) \\
69^{* \wedge}(64-76)\end{array}$ & $\begin{array}{r}14.5 *(14-17) \\
14(12-16)\end{array}$ & $\begin{array}{l}37.5 *(37.4-37.6) \\
37.4 *(37.4-37.5)\end{array}$ \\
\hline 45 & $\begin{array}{l}\mathrm{T} 1 \\
\mathrm{~T} 2\end{array}$ & $\begin{array}{r}59(56-65) \\
53^{\wedge}(50-60)\end{array}$ & $\begin{array}{l}13.5(12-16) \\
13.5(12-15)\end{array}$ & $\begin{array}{l}37.1(37.1-37.2) \\
37.2(37.1-37.3)\end{array}$ \\
\hline 60 & $\begin{array}{l}\mathrm{T} 1 \\
\mathrm{~T} 2\end{array}$ & $\begin{array}{r}59(53-63) \\
53^{\wedge}(50-54)\end{array}$ & $\begin{array}{l}13.5(13-14) \\
13.5(11-14)\end{array}$ & $\begin{array}{l}37.1(37.1-37.2) \\
37.2(37.1-37.3)\end{array}$ \\
\hline 75 & $\begin{array}{l}\mathrm{T} 1 \\
\mathrm{~T} 2\end{array}$ & $\begin{array}{r}61(55-64) \\
52^{\wedge}(50-56)\end{array}$ & $\begin{array}{l}12.5(12-13) \\
13.5(12-14)\end{array}$ & $\begin{array}{l}37.2(36.9-37.3) \\
37.1(37.1-37.2)\end{array}$ \\
\hline 90 & $\begin{array}{l}\text { T1 } \\
\text { T2 }\end{array}$ & $\begin{array}{r}62(57-67) \\
53^{\wedge}(50-58)\end{array}$ & $\begin{array}{l}12.5(11-13) \\
12.5(12-14)\end{array}$ & $\begin{array}{l}37.1(37.0-37.3) \\
37.1(37.1-37.2)\end{array}$ \\
\hline 105 & $\begin{array}{l}\text { T1 } \\
\text { T2 }\end{array}$ & $\begin{array}{r}59.5(56-64) \\
52.5^{\wedge}(50-54)\end{array}$ & $\begin{array}{r}13(12-13) \\
12.5(12-14)\end{array}$ & $\begin{array}{l}37.2(36.9-37.2) \\
37.1(37.1-37.2)\end{array}$ \\
\hline 120 & $\begin{array}{l}\mathrm{T} 1 \\
\mathrm{~T} 2\end{array}$ & $\begin{array}{r}59(56-62) \\
52^{\wedge}(50-54)\end{array}$ & $\begin{array}{r}12(12-13) \\
12.5(11-14)\end{array}$ & $\begin{array}{l}37.2(37.0-37.2) \\
37.1(37.1-37.2)\end{array}$ \\
\hline
\end{tabular}

* significant difference $(\mathrm{P}<0.05)$ from baseline values; ${ }^{\wedge}$ significant difference between groups $\mathrm{T} 1$ and $\mathrm{T} 2(\mathrm{P}<0.05)$.

following tramadol injection $(\mathrm{P}<0.05)$. Comparisons of the two groups indicated that HR was significantly lower in camels receiving the higher dose of tramadol $(2 \mathrm{mg} / \mathrm{kg})$ than in those receiving the lower dose $(1 \mathrm{mg} / \mathrm{kg})(\mathrm{P}<0.05)$.

\section{DISCUSSION}

Caudal epidural tramadol administration has been performed in different species such as horses (Natalini \& Robinson, 2002), cattle (Baniadam et al., 2010; Bigham et al., 2010), sheep (Habibian et al., 2011), goats (Dehkordi et al., 2012), cats (Castro et al., 2009) and dogs (Guedes et al., 2005; Natalini et al., 2007). However, to the authors' knowledge, this is the first study to investigate the analgesic effect of epidural administration of tramadol (monotherapy) in camels.

Assessment and recognition of pain in animals is difficult and challenging because unlike humans, animals are unable to communicate verbally and there is variability in their behavioural responses (Landa, 2012). The interpretation of the results of experimental pain studies can be influenced by the methods used to evaluate the analgesic effects of drugs. The method chosen for pain assessment should be valid and sensitive as well as quick and easy to perform in clinical practice 
(Schofield \& Williams, 2002). In this stu$\mathrm{dy}$, analgesic effects of epidural tramadol were assessed by the responses to superficial and deep pinpricking stimuli.

Based on the results of this study, extent of analgesia caused by epidural injection of tramadol is dose-dependent. The dose of tramadol chosen for this study was based on animal studies where tramadol was used at doses of 1.0 to $2.0 \mathrm{mg} / \mathrm{kg}$ (Natalini et al., 2007; Vettorato et al., 2010). As seen here, complete analgesia was achieved in the tail, anus and perineum of the camels receiving tramadol at the dose of $2 \mathrm{mg} / \mathrm{kg}$, while administration of the dose of $1 \mathrm{mg} / \mathrm{kg}$ resulted in complete antinociception only in the tail. Neither dose of tramadol provided adequate hind limb analgesia. The degree of analgesia and the area affected by epidurally administered drugs may be influenced by several factors. Epidural distribution and extent of anatomic effects of injected drugs mainly relies on anatomic factors including size of the epidural space, abundance of epidural fat, fibrosis of epidural tissue, and differences in negative epidural pressure. Moreover, the total mass (volume $\times$ concentration) of the anaesthetic agent is also of great importance in the induction of caudal analgesia (Hall et al., 2001; Lee et al., 2003).

The mean onset of complete perineal analgesia produced by tramadol $(2 \mathrm{mg} / \mathrm{kg})$ in camels was $22 \pm 2.55 \mathrm{~min}$. The reported mean onsets of most other epidurally administered anaesthetics in camels were $12.5 \pm 1.89$ and $8 \mathrm{~min}$ for lidocaine and ketamine respectively (Azari et al., 2012; 2014). Our treatment with tramadol produced a mean of $65 \pm 8.66$ min complete perineal analgesia in camels. In two separate studies, Azari et al. (2012; 2014) have reported that ketamine and lidocaine provided periods of perineal analgesia lasting for 30 and $55 \pm 5.4 \mathrm{~min}$, respectively. When compared with ketamine and lidocaine, caudal epidural tramadol resulted in longer duration of analgesia in camels; however, onset of analgesia was slower. In a similar study performed to evaluate the analgesic effects of caudal epidural tramadol (dose: $2 \mathrm{mg} / \mathrm{kg}$ ) in cattle, Baniadam et al. (2010) reported the mean onset of 6-12 min and a mean duration of $30 \mathrm{~min}$ for perineal analgesia. So the same dose of tramadol $(2 \mathrm{mg} / \mathrm{kg}$ ) produced faster but shorter duration of antinociception in cattle, in comparison to our results in camels. These variations may be attributed to anatomical and physiological differences between the two species.

Duration of action of drugs administered epidurally mostly relies on their lipid solubility (Valverde, 2008). Low lipophilicity of drugs like morphine causes them to bind to a lesser extent to fat and provide a higher concentration gradient that increases absorption into the CSF (Valverde, 2008). Tramadol has a lipid solubility similar to that of morphine, and therefore slow onset and long duration of action would be expected (Valverde, 2008; Castro et al., 2009).

Tramadol is extensively metabolised in the liver before entering systemic circulation (García-Quetglas et al., 2007). Its active metabolite, $O$-desmethyltramadol (M1), is a significantly more potent $\mu$ receptor agonist than tramadol itself (Scott \& Perry, 2000). The rapid and effective production of M1 metabolite has been observed after both intravenous and extradural administration of tramadol (Vettorato et al., 2010). The sedative (mild to deep sedation) and analgesic effect observed in the current study could be attributed to production of M1.

An ideal epidural analgesic would produce effective anti-nociception with 
minimal adverse effects (Kehlet \& Holte, 2001). Compared to other $\mu$-receptor agonists such as morphine and codeine, respiratory depression and bradycardia with tramadol is lower at the recommended dosage (Scott \& Perry, 2000; Demiraran et al., 2005). Despite intravenous tramadol that has been found to induce CNS excitation, epidural administration of tramadol has been shown to provide long-lasting analgesia without CNS excitation and changes in behavior (Natalini \& Robinson, 2002; Seo et al., 2011). In a study conducted by Elghazali et al. (2008), no drug-associated adverse effect was observed following intravenous and intramuscular tramadol in camels. According to the studies performed in cattle (Baniadam et al., 2010), horses (Natalini \& Robinson, 2002), donkeys (Faleiros et al., 2004) and dogs (Guedes et al., 2005), epidural tramadol had no effect on HR, RR and RT. However, based on the results of the present study, there was an increase in $\mathrm{HR}, \mathrm{RR}$ and $\mathrm{RT}$ in the first 15 to $30 \mathrm{~min}$ of the experiment and soon after that, the increasing trend stopped. The authors proposed that this effect could be associated with restraint and injection stress. Compared to ketamine, lesser degrees of ataxia occurred following epidural tramadol in dromedaries (Azari et al., 2012).

In conclusion, we have shown that caudal epidural administration of tramadol produced a dose dependent decrease in the response to pin pricking of the tail, anus, and perineum in dromedary camels. Epidural tramadol at a dose of $2 \mathrm{mg} / \mathrm{kg}$ would provide suitable analgesia for postoperative manipulations in any of these regions in standing position. However, further studies are required to determine whether caudal epidural administration of tramadol would solely provide appropriate analgesia to perform obstetrical manipulations in standing dromedary camels.

\section{REFERENCES}

Altunkaya, H., Y. Ozer, E. Kargi \& O. Babuccu, 2003. Comparison of local anaesthetic effects of tramadol with prilocaine for minor surgical procedures. British Journal of Anaesthesia, 90, 320-322.

Azari, O., M. M. Molaei, L. Emadi, E. Sakhaee \& M. Esmaeili, 2012. Epidural ketamine in the dromedary camel. Veterinary Anaesthesia and Analgesia, 39, 291-295.

Azari, O., M. M. Molaei \& H. Roshani, 2014. Caudal epidural analgesia using lidocaine alone and in combination with tramadol in dromedary camels. Iranian Journal of Veterinary Surgery, 9, 27-32.

Baniadam, A., F. S. Afshar \& F. Ahmadian, 2010. Analgesic effects of tramadol hydrochloride administered via caudal epidural injection in healthy adult cattle. American Journal of Veterinary Research, 71, 720 725.

Bigham, A. S., S. Habibian, F. Ghasemian \& S. Layeghi, 2010. Caudal epidural injection of lidocaine, tramadol, and lidocainetramadol for epidural anesthesia in cattle. Journal of Veterinary Pharmacology and Therapeutics, 33, 439-443.

Castro, D. S., M. F. Silva, A. C. Shih, P. P. Motta, M. V. Pires \& P. O. Scherer, 2009. Comparison between the analgesic effects of morphine and tramadol delivered epidurally in cats receiving a standardized noxious stimulation. Journal of Feline Medicine \& Surgery, 11, 948-953.

Dehghani, S. \& A. Bigham, 2009. Comparison of caudal epidural analgesia by use of lidocaine versus a lidocaine-magnesium sulfate combination in cattle. American Journal of Veterinary Research, 70, 194-197.

Dehkordi, S. H., A. Bigham-Sadegh \& R. Gerami, 2012. Evaluation of anti-nociceptive effect of epidural tramadol, tramadol-lidocaine and lidocaine in goats. 
Analgesic and sedative effects of caudal epidural tramadol in dromedary camels

Veterinary Anaesthesia and Analgesia, 39, 106-110.

Demiraran, Y., B. Kocaman \& R. Y. Akman, 2005. A comparison of the postoperative analgesic efficacy of single-dose epidural tramadol versus morphine in children. British Journal of Anaesthesia, 95, 510-513.

Elghazali, M., I. M. Barezaik, A. A. Hadi, F.M. Eltayeb, J. Al Masri \& I. A. Wasfi, 2008. The pharmacokinetics, metabolism and urinary detection time of tramadol in camels. The Veterinary Journal, 178, 272 277.

Faleiros, R. R., G. E. S. Alves, V. G. Andrade, M. R. F. Matos, C. A. De Marval, C. E. Braga \& C. C. Natalini, 2004. Epidural analgesia with tramadol and morphine in a donkey with oncologic pain. Journal of Veterinary Emergency and Critical Care, 14, S1-S17.

García-Quetglas, E., J. R. Azanza, B. Sádaba, M. J. Muñoz, I. Gil \& M. A. Campanero, 2007. Pharmacokinetics of tramadol enantiomers and their respective phase I metabolites in relation to CYP2D6 phenotype. Pharmacological Research, 55, 122 130.

Guedes, A. G. P., C. C. Natalini, E. P. Robinson, S. D. L. Alves \& S. T. Oliveira, 2005. Epidural administration of tramadol as an analgesic technique in dogs submitted to stifle surgery. International Journal of Applied Research in Veterinary Medicine, 3, 351-359.

Habibian, S., A. S. Bigham \& E. Aali, 2011. Comparison of lidocaine, tramadol, and lidocaine-tramadol for epidural analgesia in lambs. Research in Veterinary Science, 91, 434-438.

Hall, L. W., K. W. Clarke \& C. M. Trim, 2001. General principles of local analgesia. In: Veterinary Anaesthesia, W. B. Saunders, London, pp. 225-247.

Kadim, I. T., O. Mahgoub \& R. W. Purchas, 2008. A review of the growth, and of the carcass and meat quality characteristics of the one-humped camel (Camelus dromedaries). Meat Science, 80, 555-569.
Kehlet, H. \& K. Holte, 2001. Effect of postoperative analgesia on surgical outcome British Journal of Anaesthesia, 87, 62-72.

Landa, L., 2012. Pain in domestic animals and how to assess it: A review. Veterinarni Medicina, 57, 185-192.

Lee, I., T. Yoshiuchi, N. Yamagishi, K. Oboshi, Y. Ayukawa, N. Sasaki \& H. Yamada, 2003. Analgesic effect of caudal epidural ketamine in cattle. Journal of Veterinary Science, 4, 261-264.

Mburu, D. N., J. W. Ochieng, S. G. Kuria, H. Jianlin, B. Kaufmann, J. E. O. Rege \& O Hanotte, 2003. Genetic diversity and relationships of indigenous Kenyan camel (Camelus dromedarius) populations: implications for their classification. Animal Genetics, 34, 26-32.

Natalini, C. C. \& E. P. Robinson, 2002. Effects of epidural opioid analgesics on heart rate, arterial blood pressure, respiratory rate, body temperature, and behavior in horses. Veterinary Therapeutics: Research in Applied Veterinary Medicine, 4, 364 375.

Natalini, C. C., A. S. Polydoro \& N. Crosignani, 2007. Antinociceptive effects of epidural tramadol administration in dogs as an analgesic technique for experimental stifle surgery. Acta Scientiae Veterinariae, 35, 189-195.

Pathan, H. \& J. Williams, 2012. Basic opioid pharmacology: an update. British Journal of Pain, 6, 11-16.

Pereira, F. G., S. A. Greene, M. M. McEwen \& R. Keegan, 2006. Analgesia and anesthesia in camelids. Small Ruminant Research, 61, 227-233.

Raffa, R. B., E. Friderichs, W. Reimann, R. P. Shank, E. E. Codd, J.L. Vaught, H.I. Jacoby \& N. Selve, 1993. Complementary and synergistic antinociceptive interaction between the enantiomers of tramadol. Journal of Pharmacology and Experimental Therapeutics, 267, 331-340.

Schofield, J. C. \& V.M. Williams, 2002. Analgesic best practice for the use of animals in research and teaching: An interpretative 
international literature review. Biosecurity New Zealand, http://www.fao.org/filead$\mathrm{min} /$ user_upload/animalwelfare/analgesicpractice.pdf (5 December 2016 date last accessed).

Scott, L. J. \& C. M. Perry, 2000. Tramadol: A review of its use in preoperative pain. Drugs, 60, 139-176.

Seo, J. P., W. G. Son, S. Gang \& I. Lee, 2011. Sedative and analgesic effects of intravenous xylazine and tramadol on horses. Journal of Veterinary Science, 12, 281286.

Valverde, A., 2008. Epidural analgesia and anesthesia in dogs and cats. Veterinary Clinics of North America: Small Animal Practice, 38, 1205-1230.

Vettorato, E., A. Zonca, M. Isola, R. Villa, M. Gallo, G. Ravasio, M. Beccaglia, C.
Montesissa \& P. Cagnardi, 2010. Pharma-

cokinetics and efficacy of intravenous and extradural tramadol in dogs. The Veterinary Journal, 183, 310-315.

Paper received 20.04.2017; accepted for publication 05.06.2017

\section{Correspondence:}

Sajad Seyyedin

Faculty of Veterinary Medicine,

Shahid Bahonar University of Kerman, Iran,

P. O. Box 76169133,

tel.: +989137581242 ,

e-mail: s.seyyedin1991@gmail.com 